\title{
The time to focus on the imaging of posterior vitreous and vitreoretinal interface by optical coherence tomography
}

\begin{abstract}
Vitreous humor plays important role in ocular in growth, the maintaining of ocular media transparency and tonus. It is difficult to exactly assess the relationship between the vitreous and the macula with only slit lamp bio microscopy. Spectral domain optical coherence tomography provides to evaluate the vitreomacular interface and posterior vitreous. Some vitreomacular interface diseases or the risk factors for these can be demonstrated the imaging of posterior vitreous by optical coherence tomography.
\end{abstract}

Keywords: posterior vitreous, imaging, vitreoretinal interface, vitreomacular disease, optical coherence tomography
Volume 6 Issue 5 - 2017

Burak Turgut

Department of Ophthalmology, Firat University, Turkey

Correspondence: Burak Turgut, Associate Professor of Ophthalmology, Firat University, Faculty of Medicine, Department of Ophthalmology, 23119 Elazig, Turkey, Tel +904242333555,

Email burakturgut@firat.edu.tr,drburakturgut@gmail.com

Received: March 08, 2017 | Published: April 06, 2017

\section{Abbreviations}

OCT, optical coherence tomography; VRI, vitreo-retinal interface; VMA, vitreo-macular adhesion; APVD, anomalous posterior vitreous detachment; VMTS, vitreomacular traction syndrome; $\mathrm{MH}$, macular hole; MP, macular pucker; AMD, age-related macular degeneration; DME, diabetic macular edema; RVO, retinal vein occlusion; DR, diabetic retinopathy; PVS, posterior vitreo-schisis; MRS, myopic retino schisis; VPTS, vitreo-papillary traction syndrome; NVD, neovascularization disk; NVE, neo-vascularization elsewhere; PDVR, proliferative diabetic vitreo-retinopathy; NPDR, non-proliferative diabetic retinopathy; PVD, posterior vitreous detachment; ERM, epiretinal membrane; CME, cystoid macular edema; PPVP, posterior precortical vitreous pocket; TTPH, thickened taut posterior hyaloid; PPV, pars plana vitrectomy; PTILM, postvitrectomy taut internal limiting membrane

\section{Introduction}

Vitreous humor that is located between the lens and retina is a clear gel-like substance that occupies a large portion of the intraocular space $(4.0 \mathrm{~mL}$ of ocular volume). It plays in role ocular ingrowth, the maintaining of ocular media transparency and tonus, and it provides some refractive media. Vitreous is formed by water (98-99\%), the meshwork of collagen fibril with hyaluronic acid. It most firmly attached to optic disc, macula, over macular blood vessels and the vitreous base. ${ }^{1}$ It is difficult to exactly assess the relationship between the vitreous and the macula with only slit lamp bio microscopy because the vitreous is a transparent and clear tissue. Spectral domain optical coherence tomography (OCT) provides to observe and to evaluate the vitreoretinal interface (VRI) and posterior vitreous. Some VRI diseases or the risk factors for these can be demonstrated by OCT of posterior vitreous.

\section{Vitreo-macular adhesion (VMA) and anomalous posterior vitreous detachment (APVD)}

Vitreomacular adhesion is one of the results of APVD. Although VMA's itself is not dangerous, it can cause vitreomacular traction syndrome (VMTS), and eventually severe retinal damage and visual loss. Additionally, it has been considered that the symptomatic VMA could contribute to the development of macular hole $(\mathrm{MH})$ and macular pucker (MP). VMA may also be associated with neovascular age-related macular degeneration (AMD), diabetic macular edema (DME), retinal vein occlusion (RVO), and diabetic retinopathy (DR). ${ }^{2-}$ ${ }^{10}$ According to "Classification of Vitreomacular Adhesion, Traction, and Macular Hole" by "The International Vitreomacular Traction StudyGroup", VMA is diagnosed in the presence at least one of those findings in OCT, partial vitreous detachment as indicated by elevation of cortical vitreous above the retinal surface in the perifoveal area; persistent vitreous attachment to the macula within a $3-\mathrm{mm}$ radius from the center of the fovea; acute angle between posterior hyaloid and inner retinal surface; absence of changes in foveal contour or retinal morphology. ${ }^{2}$

APVD is due to an imbalance between the degree of gel liquefaction and weakening of vitreoretinal adhesion. If the degree of vitreous liquefaction overwhelms the degree of weakening of vitreoretinal adherence, anomalous and strong vitreoretinal traction at this interface may cause VTMS, retinal or intravitreal hemorrhages in especially in ischemic and diabetic retinopathies, DME, posterior vitreoschisis (PVS), myopic retinoschisis (MRS), MP, MH, periphery retinal tears/ detachments, vitreopapillary traction syndrome (VPTS), neovascular AMD. Additionally, it can aggravate the neovascularization in disk (NVD) and elsewhere retina (NVE) in especially in proliferative vitreoretinopathy (PDVR) and retinal vein occlusion (RVO). ${ }^{3-10}$

\section{Posterior vitreo-schisis (PVS)}

Posterior vitreoschisis is the splitting of the posterior vitreous cortex. PVS is the consequence of APVD with strong VMA, if syneresis occurs. When the posterior vitreous cortex splits, the leaving the outermost layer of PVS remains attached to the macula. The remainder anterior portion of the posterior vitreous cortex collapses forward. The split in the posterior vitreous cortex can induce some vitreomacular pathologies. ${ }^{11-13}$ It has been reported that PVS was detected in the cases with especially DME, PDVR, retinovascular 
disease and Eale's disease. PVS can occur much less frequently in the patients with neovascular AMD and nonproliferative diabetic retinopathy (NPDR). As PVS was detected in half of eyes with MH and MP,it has been considered that APVD with vitreoschisis might play role in the pathogenesis of these. ${ }^{13-18}$

\section{Vitreo-macular traction syndrome (VTMS)}

Vitreomacular traction syndrome is a disorder of the VRI characterized by at least one of those OCT findingsaccording to "Classification of Vitreomacular Adhesion, Traction, and Macular Hole" of "The International Vitreomacular Traction StudyGroup", an incomplete posterior vitreous detachment (PVD) (elevation of cortical vitreous above the retinal surface in the perifoveal area); persistent vitreous attachment to the macula within a $3-\mathrm{mm}$ radius from the center of the fovea; acute angle between posterior hyaloid and inner retinal surface; an abnormally strong adherence of the posterior hyaloid on the macula; the anteroposterior traction exerted by the syneretic vitreous pulling at adherent sites on the macula; presence of changes in foveal contour or retinal morphology including the distortion of foveal surface; intraretinal structural changes including pseudocyst formation, elevation of fovea from the RPE; and absence of full thickness interruption of all retinal layers. Retinal thickening underlying VMTS is greatest. If VMTS involves the fovea, focal foveal distortion is greater. ${ }^{2,19}$ VMTS can lead to formation of a full/partialthickness $\mathrm{MH}$, epiretinal membrane (ERM), and cystoid macular edema (CME). It usually occurs in cases with age-related vitreous changes and vitreous liquefaction, high myopia, neovascular AMD, DME, DR, and RVO. OCT exactly identifies and details VMTS. ${ }^{2,19}$

\section{Posterior precortical vitreous pocket (PPVP)}

The posterior precortical vitreous pocket, called also 'bursa premacularis" is a liquefied lacuna anterior to the macular area. It is physiologically present in the vitreous of adultsexcept newborns. PPVP can be confirmed by spectral-domain OCT. PPVP is observedat convex configrationin posterior vitreous cortex detached from macula. The premacular thin vitreous cortex is the posterior wall of the PPVP. Its anterior wall is formed by the vitreous gel..$^{20-26}$ It has been demonstrated that PPVP plays role in some VRI disorders including idiopathic ERM, DME, PDVR, foveal cyst and MH. These pathologies may be explained by the posterior wall of the PPVP acting as an ERM on the macula or the residual premacular vitreous cortex causing trampoline-like traction on the perifovea. ${ }^{20-26}$

\section{Taut thickened posterior hyaloid (TTPH)}

Thickened taut posterior hyaloid is firstly described by Lewis et al in the eyes with DME that had a clinically "thickened, taut, and glistening premacular posterior hyaloid" in the absence of signs of VTMS. In this case of TTPH, posterior hyaloid usually seems as a glistening reflex in ophthalmoscopy. Striae limited only to posterior hyaloid but not to retina can be observed. These sitriae in TTPH is not involve the retina or retinal vasculature, as distinct from eyes with ERMs. Recent reports demonstrated that pars plana vitrectomy (PPV) may be an efficacious in the treatment for DME associated with TTPH. Kaiser et al. ${ }^{6}$ found that eyes with a clinical diagnosis of TTPH had shallow elevation of a partially detached hyaloid with VMAs. Patients with a TTPH may have the partial posterior hyaloid separation and underlying intraretinal or subretinal fluid and retinal thickening without edema as OCT finding. ${ }^{27-30}$ Recently, Lewis et al. reported that PPV with removal of the TTPH provided a complete resolution in $80 \%$ of eyes with DME associated with TTPH. ${ }^{27}$ In another study, it has been reported that PPV provided complete resolution in $81 \%$ of eyes with DME associated with TTPH. ${ }^{29}$ However, the results of the surgery is depend on the duration of edema and the presence of the macular ischemia, atrophy, and postoperative ERMs. ${ }^{30}$

\section{Postvitrectomy taut internal limiting membrane (PTILM)}

Postvitrectomy taut ILM is an OCT entity that can cause persistent DME after PPV with prior hyaloid removal. This finding can be distingiushed from a TTPH and VMTS by the absence of an attached or partially attached hyaloid. Additionally, PTILM has hyper-reflective than normal reflective ILM and it has not any VMA and diffuse retinal edema. ${ }^{31,32}$. Postvitrectomy taut ILM usually develops in first one-two months following PPV with hyaloid removal. It is nonresponsive to non-surgical therapoetic applications such as laser photocoagulation, intravitreal injections of corticosteroid and anti-VEGF agents. In focal type of PTILM, ILM exists striae while in diffuse type, there is a glistening in the posterior pole. OCT reveals the edema in our retina without manifest traction. ${ }^{31,32}$ It has been considered that PTILM might be develop due to the tangential traction of the ILM onto the distant retina because ILM has no elasticity. Based on the histopathological examinations of PTILMs, it has been observed that PTILM has contractile cellular elements such as retinal pigment epithelium/glia cells having smooth muscle actin. ${ }^{31,32}$

\section{vitreo-papillary traction syndrome (VPTS)}

Vitreopapillary traction syndrome is characterized by the traction of posterior hyaloid on the optic nerve head or an incomplete posterior vitreous detachment. VPTS can cause the appearance of papilledema because of tenting of the papillary rim and intrapapillary and peripapillary hemorrhages. Although VPTS may be idiopathic or isolated. It can also occur as secondary to APVD in PDVR and central RVO. In ophthalmoscopy and B scan ocular ultrasonography, optic disc traction may be overlooked. However, the traction in VPTS can be easily showed by OCT (Table 1). ${ }^{33-40}$

Table I Disorders of posterior vitreous or VRI and associated pathologies

\begin{tabular}{|c|c|c|c|c|c|c|c|}
\hline VMA & APVD & PVS & VTMS & PPVP & TTPH & PTILM & PPTS \\
\hline \multirow[t]{2}{*}{$\cdot \mathrm{VMTS}$} & $\cdot$ MRS & $\cdot$ DME & $\cdot \mathrm{MH}$ & - Idiopathic ERM & $\cdot$ DME & $\begin{array}{l}\text { - Prior PPV with hyaloid } \\
\text { removal }\end{array}$ & · Idiopathic/isolated \\
\hline & & & & & & & $\begin{array}{l}\text {-APVD in DVRP and } \\
\text { central RVO }\end{array}$ \\
\hline$\cdot \mathrm{MH}$ & VVTMS & $\cdot$ PDVR & $\cdot$ ERM & $\cdot$ DME & & - Persistent DME & \\
\hline$\cdot M P$ & $\begin{array}{l}\cdot \text { Retinal/ } \\
\text { intravitreal } \\
\text { hemorrhages }\end{array}$ & $\cdot \operatorname{RVD}$ & $\cdot \mathrm{CME}$ & $\cdot$ PDVR & & $\begin{array}{l}\text { - Prior PPV with hyaloid } \\
\text { removal }\end{array}$ & \\
\hline
\end{tabular}


Table Continued...

\begin{tabular}{|c|c|c|c|c|c|c|c|}
\hline VMA & APVD & PVS & VTMS & PPVP & TTPH & PTILM & PPTS \\
\hline AMD & DME & - Eale's & · High myopia & · Fovealcyst & & & \\
\hline$\cdot$ DME & $\cdot$ PVS & $\cdot \mathrm{MH}$ & AMD & $\cdot \mathrm{MH}$ & & & \\
\hline$\cdot$ RVO & $\cdot M P$ & $\cdot M P$ & - DME & & & & \\
\hline \multirow[t]{5}{*}{$\cdot \mathrm{DR}$} & $\cdot \mathrm{MH}$ & AMD & $\cdot \mathrm{DR}$ & & & & \\
\hline & $\begin{array}{l}\text { - Periphery } \\
\text { retinaltears/ } \\
\text { detachment }\end{array}$ & $\cdot$ NPDR & - RVO & & & & \\
\hline & ·VPTS & DME & & & & & \\
\hline & $\cdot$ NVE NVD & $V R$ and $R$ & & & & & \\
\hline & AMD & & & & & & \\
\hline
\end{tabular}

\section{Conclusion}

Optical coherence tomography is noninvasive diagnostic tool for the imaging of posterior vitreous, retina and choroid. In the usage of OCT, the interest has been concentrated on the imaging of retina, andrecently of choroid. However, it's the time to focus on the imaging of posterior vitreous. Because OCT can be used for the early detection of the diseases of VRI and posterior vitreous.

Table abbreviations: OCT, optical coherence tomography; VRI, vitreoretinal interface; VMA, vitreomacular adhesion; APVD, anomalous posterior vitreous detachment; PVS, posterior vitreoschisis; VTMS, vitreomacular traction syndrome; TTPH, taut thickened posterior hyaloid; PTILM, postvitrectomy taut ilm; DME, diabetic macular edema; AMD, age-related macular degeneration; MP, macular pucker; MH, macular hole; VPTS, vitreopapillary traction syndrome; PDVR, proliferative diabetic vitreoretinopathy; CME, cystoid macular edema; ERM, epiretinal membrane; RVO, retinal vein occlusion; PPV, pars plana vitrectomy; MRS, myopic retinoschisis; DR, diabetic retinopathy; RVD, retinovascular disease

\section{Funding}

None.

\section{Acknowledgments}

None.

\section{Conflicts of interest}

Author declares that there is no conflict of interest.

\section{References}

1. Sebag J. Vitreous anatomy and pathology. In:M Yanoff \& JS Duker, editors. Ophthalmology. 3rd ed. Mosby Elsevier, Edinburgh:USA;2009. p. 766-773.

2. Duker JS, Kaiser PK, Binder S, et al. The International Vitreomacular Traction Study Group Classification of Vitreomacular Adhesion, Traction, and Macular Hole. Ophthalmology. 2013;120(12):2611-2619.

3. Sebag J. Anomalous posterior vitreous detachment:a unifying concept in vitreo-retinal disease. Graefes Arch Clin Exp Ophthalmol. 2004;242(8):690-698.
4. Sebag J. Vitreous anatomy, aging, and anomalous posterior vitreous detachment. In:DA Dartt, editors. Encyclopedia of the Eye, Vol 4 Academic Press, Oxford:USA; 2010: p. 307-315.

5. Massin P, Duguid G, Erginay A, et al. Optical coherence tomography for evaluating diabetic macular edema before and after vitrectomy. Am J Ophthalmol. 2003;135(2):169-177.

6. Kaiser PK, Riemann CD, Sears JE, et al. Macular traction detachment and diabetic macular edema associated with posterior hyaloidal traction. Am J Ophthalmol. 2001;131(1):44-49.

7. Benhamou N, Massin P, Haouchine B, et al. Macular retinoschisis in highly myopic eyes. Am J Ophthalmol. 2002;133(6):794-800.

8. Johnson MW. Posterior vitreous detachment:evolution and complications of its early stages. Am J Ophthalmol. 2010;149(3):371-382.

9. Krebs I, Brannath W, Glittenberg C, et al. Posterior vitreomacular adhesion:a potential risk factor for exudative age-related macular degeneration?. Am J Ophthalmol. 2007;144(5):741-746.

10. Mojana F, Cheng L, Bartsch DU, et al. The role of abnormal vitreomacular adhesion in age-related macular degeneration:spectral optical coherence tomography and surgical results. Am J Ophthalmol. 2008;146(2):218227.

11. Kakehashi A, Schepens CL, de Sousa-Neto A, et al. Biomicroscopic findings of posterior vitreoschisis. Ophthalmic Surg. 1993;24(12):846850 .

12. Chu TG, Lopez PF, Cano MR, et al. Posterior vitreoschisis. An echographic finding in proliferative diabetic retinopathy. Ophthalmology. 1996;103(2):315-322.

13. Schwartz SD, Alexander R, Hiscott $P$, et al. Recognition of vitreoschisis in proliferative diabetic retinopathy. A useful landmark in vitrectomy for diabetic traction retinal detachment. Ophthalmology. 1996;103(2):323328.

14. Badrinath SS, Gopal L, Sharma T, et al. Vitreoschisis in Eales' disease:pathogenic role and significance in surgery. Retina. 1999;19(1):51-54.

15. Sebag J, Gupta P, Rosen R, et al. Macular holes and macular pucker-the role of vitreoschisis as imaged by optical coherence tomography/scanning laser ophthalmoscopy. Trans Am Ophthalmol Soc. 2007;105:121-129.

16. Sebag J. Anomalous posterior vitreous detachment:a unifying concept in vitreo-retinal disease. Graefes Arch Clin Exp Ophthalmol. 2004;242(8):690-698. 
17. Sebag J. Vitreoschisis. Graefes Arch Clin Exp Ophthalmol. 2008;246(3):329-332.

18. Gupta P, Yee KM, Garcia P, et al. Vitreoschisis in macular diseases. $B r J$ Ophthalmol. 2011;95(3):376-380.

19. Bottós J, Elizalde J, Arevalo JF, et al. Vitreomacular Traction Syndrome J Ophthalmic Vis Res. 2012;7(2):148-161.

20. Kishi S, Shimizu K. Posterior precortical vitreous pocket. Arch Ophthalmol. 1990;108(7):979-982.

21. Schaal KB, Pang CE, Pozzoni MC, et al. The premacular bursa's shape revealed in vivo by swept-source optical coherence tomography. Ophthalmology. 2014;121(5):1020-1028.

22. Kishi S, Shimizu K. Clinical manifestations of posterior precortical vitreous pocket in proliferative diabetic retinopathy. Ophthalmology. 1993;100(2):225-229.

23. Kishi S, Shimizu K. Oval defect in detached posterior hyaloid membrane in idiopathic preretinal macular fibrosis. Am J Ophthalmol. 1994;118(4):451-456.

24. Kishi S, Hagimura N, Shimizu K. The role of the premacular liquefied pocket and premacular vitreous cortex in idiopathic macular hole development. Am J Ophthalmol. 1996;122(5):622-628.

25. Kishi S, Demaria C, Shimizu K. Vitreous cortex remnants at the fove after spontaneous vitreous detachment. Int Ophthalmol. 1986;9(4):253260.

26. Kishi S. Impact of swept source optical coherence tomography on Ophthalmology. Taiwan Journal of Ophthalmology. 2016;6:58-68.

27. Lewis H, Abrams GW, Blumenkranz MS, et al. Vitrectomy for diabetic macular traction and edema associated with posterior hyaloidal traction. Ophthalmology. 1992;99(5):753-759.

28. Thomas D, Bunce C, Moorman C, et al. Frequency and associations of a taut thickened posterior hyaloid, partial vitreomacular separation, and subretinal fluid in patients with diabetic macular edema. Retina. 2005;25(7):883-888
29. Pendergast SD, Hassan TS, Williams GA, et al. Vitrectomy for diffuse diabetic macular edema associated with a taut premacular posterior hyaloid. Am J Ophthamol. 2000;130(2):178-186.

30. Harbour JW, Smiddy WE, Flynn HW, et al. Vitrectomy for diabetic macular edema associated with a thickened and taut posterior hyaloid membrane. Am J Ophthamol. 1996;121(4):405-413.

31. GentileRC,MilmanT,EliottD, etal.Tautinternallimitingmembranecausing diffuse diabetic macular edema after vitrectomy:Clinicopathological correlation. Ophthalmologica. 2011;226(2):64-70.

32. Boral SK, Huang SS. Diabetic vitreous surgery. Retina \& Vitreous Surgery:A Practical Guide to Theory, Practice and Management. 1st edn. Jaypee Brothers Medical Publishers, New Delhi, India; 2016. p. 55.

33. Rumelt S, Karatas M, Pikkel J, et al. A Vitreopapillary traction syndrome associated with central retinal vein occlusion. Arch Ophthalmol. 2003;121(8):1093-1097.

34. Wisotsky BJ, Magat-Gordon CB, Puklin JE. Vitreopapillary traction as a cause of elevated optic nerve head. Am J Ophthalmol. 1998;126(1):137139.

35. Katz B, Hoyt W. Gaze-evoked amarosis from vitreopapillary traction. Am J Ophthalmol. 2005;139(4):631-637.

36. Sebag J. Vitreo-papillary traction as a cause of elevated optic nerve head. Am J Ophthalmol. 1999;128(2):261-262.

37. Sebag J. Vitreous structure. In:Jakobiec F \& Albert D (Eds.), Principles and Practice of Ophthalmology. Vol 3, WB Saunders, Philadelphia, Pa, USA; 2000. p. 1786-1798.

38. Kroll P, Weigrand W, Schmidt J. Vitreopapillary traction in proliferative diabetic vitreoretinopathy. Br J Ophthalmol. 1999;83(3):261-264.

39. Schepens CL. Clinical aspects of pathologic changes in the vitreous body. Am J Ophthalmol. 1954;38(1-2):8-21.

40. Katz B, Hoyt WF. Intrapapillary and peripapillary hemorrhage in young patients with incomplete posterior vitreous detachment:signs of vitreopapillary traction. Ophthalmology. 1995;102(2):349-354. 